\title{
Self care Practices and Quality of life among men and women with Asthma; Health care Facility based study in Telangana, South India.
}

\author{
Varalakshmi Manchana ${ }^{1}$ \\ ${ }^{1}$ School of Medical Sciences, University of Hyderabad, India.
}

\begin{abstract}
Asthma is the most common among the chronic respiratory disorder that affect all age groups. Asthma management continues to be a public health challenge even today; hence it has been the focus of clinical and public health interventions. Lack of awareness about the condition, its predisposing factors, self care practices and the need for the adherence to therapeutic interventions are the most common barriers in the effective management of asthma in India and in most of the countries worldwide. Though the morbidity related to asthma is mostly preventable, its prevalence is on raise due to the neglected fact of patient education. High prevalence and poor control of asthma makes its management a major public health issue worldwide ${ }^{l}$. Uncontrolled asthma impairs individuals' quality of life and increases the frequency of asthma exacerbations ${ }^{2}$.

Aim: The present study aims to assess the impact of selected nursing interventions on self care practices and QOL in Bronchial asthma patients.

Materials and Methods: The present study adopts Quantitative Research approach with Pre-Post test control group design. Patients with confirmed diagnosis of Bronchial asthma, meeting the selected criteria were selected for target population and those willing to participate in the study were selected in to experimental $(n=100)$ and control $(n=50)$ groups were by simple random sampling. Pre tested Structured Observation checklist for the selected self care practices and the standardized asthma quality of life questionnaire $(A Q L Q(s))$ were the study instruments used for the data collection. After the pre test the tool for the selected nursing interventions was introduced to the study sample irrespective of their pre assessment practice scores and its effectiveness was tested with the post test two weeks after by the foresaid tools.

Results: The Study findings showed that the baseline Practice scores (10.88 \& 9.36) and quality of life (104.86 \&105.56) have not showed much difference between the experimental and control groups respectively. The post test Practice means for the experimental group (22.17), was much higher than post test means of Control group(9.64) with ' $t$ ' value 21.398 at $p<0.001$ level of significance. The base line QOL scores in the experimental (104.8 \pm 9.393$)$ group with the control group QOL scores (105.56 \pm 7.45$)$ show not much variation,

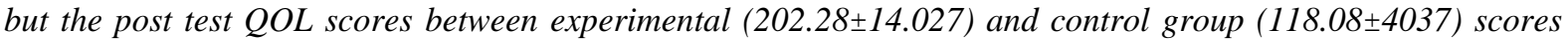
with ' $t$ ' value 41.589 at $p<0.001$ level of significance, support significant improvement in the experimental group indicating a positive influence of the selected nursing interventions. There was a significant improvement within the pre test $(3.81 \pm 1.656))$ and Post test scores in the experimental group (6.91 \pm 0.831$)$ in use of inhalation technique. The post test means between experimental (6.94) and control groups (4.92) supports the significant enhancement in the performance of inhaler use in the experimental subjects. Intervention group Pre -Post test mean Practice scores show significant enhancement in both Peak flow meter use (3.5 and 7.71) and deep breathing and coughing exercises (4.79 and 9.3).

Conclusion: Selected nursing interventions on asthma practices and quality of life show as a means to equip patients with self care practices to for their quality of life. Periodical reinforcement of their knowledge and practices may motivate patients towards behavior modification and effective asthma control.
\end{abstract}

Keywords: Bronchial asthma, Selected Nursing interventions, self-care Practices, Quality of Life

\section{Introduction}

Asthma is a rising Public Challenge with its increasing prevalence. Despite the revolutionary changes in asthma management the morbidity and mortality due to asthma is increasing worldwide ${ }^{1}$. Prevalence of asthma is over $3.5 \%$ in adults and over $5.1 \%$ in children in our country and the burden is constantly increasing ${ }^{4}$. Asthma is a chronic inflammatory disorder characterized with the intermittent and variable periods of airway obstruction. In developing countries like India, the mismatch between patients to health care providers is very wider resulting to overburdening of health care services and inability to spend time in educating the patients. Patient education is hardly pursued or possible at such circumstances with impediments like lack of time, manpower, knowledge and attitudinal barriers among health care providers. Guidelines for asthma management at primary and secondary health care levels in India have been available, they are hardly implemented ${ }^{5}$. Asthma is a leading cause of preventable suffering by acute attacks, which is possible by equipping asthma patients with 
right knowledge on self care practices. Global Initiative for Asthma Management (GINA) guidelines has also divided asthma management in to six interrelated parts of which patient education is clearly an essential component ${ }^{6}$. Improper inhalation technique and poor adherence leads to ineffective drug therapy and is closely associated with poor asthma control and ineffective asthma management. Practice based asthma education aimed to increase understanding, skill satisfaction and confidence of patient is a priority need for effective management of the condition. Compliance to treatment should be checked repeatedly as incorrect use of inhalation devices is frequently observed at all levels including patients and physicians ${ }^{7,8}$. Peak flow meter plays a prominent role in monitoring efficacy of therapy and for detecting early warning signs and onset of acute attacks, thus helps in taking appropriate measures in prevention of acute asthmatic attacks. Objective asthma monitoring with a peak flow meter is almost nonexistent in our country with less than $1 \%$ of doctors using them ${ }^{9}$.

Aim:

The study aims to evaluate the effectiveness of the nursing interventions on self care practices and asthma QOL. Objectives

1. Assess and evaluate the self care practices and QOL in Bronchial asthma patients before and after the introduction of selected nursing interventions.

2. Associate the selected demographic variables with Practices and QOL in the bronchial asthma patients.

\section{Methodology}

Patients with confirmed diagnosis of asthma, who are on inhaler therapy attending the impatient and outpatient units of the Government hospital for general and chest diseases, Hyderabad, who are in the age group between 21-60 years and willing to participate in the study were screened for recruitment into the study. Patients, who were fulfilling the inclusion criteria, were chosen by simple random sampling. Asthma Patients with co morbid conditions like COPD, allergy/sensitivity, or intolerance to any kind of asthma treatment and with acute breathing difficulties were excluded. A structured questionnaire was used to collect their demographic data and awareness on deep breathing exercises, peak flow monitoring and inhaler use. Asthma QOL was assessed by Prof. Juniper's AQLQ(s) questionnaire. Structured observational check list was used to measure the steps of deep breathing exercises, peak flow monitoring and Inhaler technique use. Institutional ethics committee approval was secured and written informed consent was obtained from each subject, following a detailed explanation of the nature and purpose of the study in a simple local language before initiating the study. The study was conducted between December' 2012 to May'2013. The tool was divided in to the following sections;

Section I- Structured Questionnaire on Demographic Variables (12 Q)

Section II; Structured Observational Checklist on the practices on peak flow monitoring, right way of using inhalers, Deep breathing \& coughing exercises. The responses performed correctly were measured as 'yes', which was scored' 1 ' and the wrong performance was 'no' scored ' 0 '.

Section III; Interviewer administered structured Asthma Quality of Life Questionnaire AQLQ(s) with Standard activities (Prof. Juniper's), investigates on how patients has been feeling in the past 14 days for asthma patients above 15 years of age, available both in English and Telugu languages. The questionnaire contains 32 questions divided in to four domains; Symptoms (12 Q), Activity Limitation (11Q), Emotional function (5 Q) and Environmental stimuli (4 Q). The responses were ranging from $1-7$, where, 1 represents maximum limitation/distress/discomfort, 4 as moderate limitation/distress/discomfort and 7 as No limitation/No discomfort/No distress.

The Nursing Interventions were organized into three sessions each of 15 minutes duration. Seven days later, subjects were provided with feedback visit for clarifications. Both groups were administered with post test two weeks (14 days) after introducing nursing interventions. Effectiveness of nursing interventions was assessed in comparison to pre - post test scores of the experimental group and comparing the post test distribution between the experimental and control groups. At the point of 4 weeks and 8 weeks from the time of intervention, subjects were facilitated with a follow-up visit for further clarification. After the completion of the data collection, the control groups were introduced with the nursing interventions and the study participants were provided with printed asthma education materials.

\section{Results}

Among the subjects $(\exp (\mathrm{n}=100) \& \operatorname{Cntr}(\mathrm{n}=50))$, maximum of $52 \%$ in the experimental group and $48 \%$ of the control group were between the age group of 51 to 60 years of age (Fig 1); 63\% were men and 37\% were women in the experimental group, where as it was $58 \%$ and $42 \%$ in the control group. In relation to occupation, in the experimental group maximum of $30 \%$ were laborers and minimum of $7 \%$ were skilled workers whereas professionals were $15 \%$ and $25 \%$ in to business. In the control group, $24 \%$ of them were 
laborers and majority of $60 \%$ were in to various other group of occupation and $6 \%$ each in business and skilled work, minimum of $4 \%$ were in professional jobs. Regarding Education about $52 \%$ and $56 \%$ were illiterates in the experimental and control groups respectively and only $4 \%$ to 5\% were recorded of having graduate level of education. Majority of the subjects' i.e.88\% in the experimental and $68 \%$ in the control groups were passive smokers and only 5 to $8 \%$ of them respectively (Fig.3) reported of not exposed to smoking. Six percent of the subjects agreed of having heard of peak flow monitoring before the intervention (Fig 6), but stated not practiced it. Thirty eight percent of them were recorded having their awareness on proper use of inhalers, but only $29 \%$ of them were using inhalers appropriately. Among them, $15 \%$ of them know the medication what they are using and the purpose of inhaler of these $20 \%$ of them could identify the purpose of relievers and preventers and $11 \%$ of them agreed for receiving education earlier from health care providers either by physician or nurses and remaining had stated to know the information on use and technique of inhalers from internet or other educative materials. None of the subjects were provided with any printed written educational material about the disease process and management. Only 2 among the subjects have accepted having been received verbal information on early signs of worsening of asthma. One patient had expressed he had learnt to use peak flow meter through a relative, who is a nurse. Among all 17\% of them stated that they have had earlier exposure to information on preventive measures for acute attacks.

The study findings (table 1) shows higher ' $t$ ' values in all the areas of Post test indicating the significant impact of the selected nursing interventions among experimental group of asthma patients in the specified areas at $\mathrm{p}<0.001$ level of significance. The total mean scores were higher in the post test scores (22.17) than the pre test practice mean scores (10.88), which signifies the effectiveness of selected nursing interventions on the practices of Bronchial asthma patients in the experimental group in related to the enhancement of the self care practice performance.

Stepwise performance scores of inhalation technique (Fig.8) in the post test show significant difference between experimental and control groups, with the experimental practice of the technique ranging between 76100 ; the control group practices between $30-84$. Table (2) indicates stepwise performance of Peak flow monitoring in the intervention group. Though the awareness in the pre test was reported to be $6 \%$, the initial two steps of placing the indicator at the base of the numbered scale and standing upright was performed 62 to $65 \%$ in the pre test; other steps with least scores recorded of $11 \%$ raised to $88 \%$ with mean percentage of $90.1 \%$. The findings in relate to the step wise improvement in the deep breathing \& coughing exercise performances among the experimental subjects(Table 3), shows step $1 \& 2$ have been in the above average performance in the control group and with the lowest performance as 24 , the scores remain to be average in the control group of subjects. QOL Domain wise comparison of F value between E.G and C.G shows significant high values in the E.G; Table (26) shows domain wise F values by ANOVA; In the area of Symptoms the F value was higher (124.030 and 34.515) in E.G than C.G; The F value was significantly high in the E.G than C.G (1753.24 and 51.185) in the domain of Activity limitation. The F value in E.G was 1838.902 in E.G, which is higher to F value of C.G (22.224). In the Emotional function domain. In the Environmental domain the F value of E.G (1516.022/ 18.229) was much higher than C.G. The QOL in over all show the F value significantly higher in E.G to C.G( 2251.095 and 61.789) supporting the effectiveness of selected nursing interventions on QOL in the experimental group compared to the Control group.

\section{Tables And Figures:}

$\mathrm{N}=150$

AGE \& GENDER Distribution

80

60

40

20

0

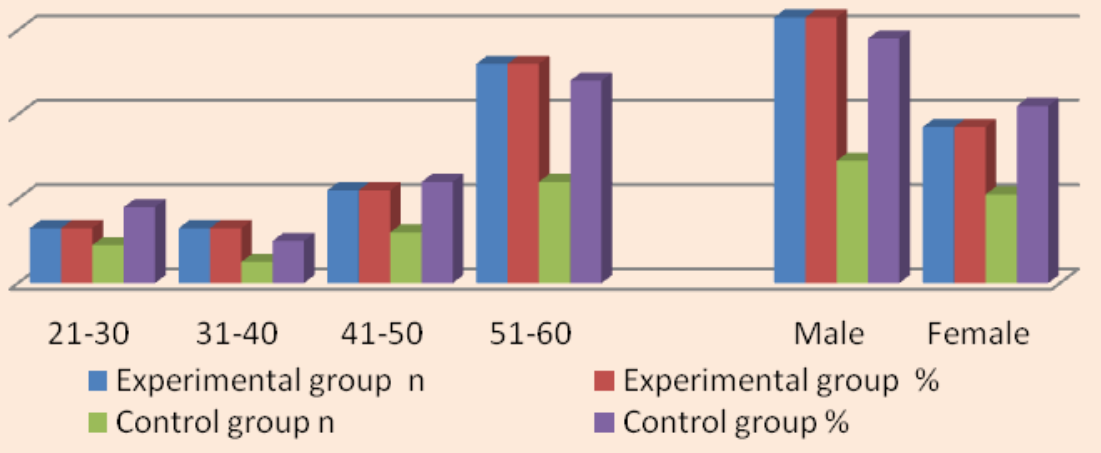

Fig 1: Distribution of Bronchial asthma patients based on their Age\& Gender $\mathrm{N}=150$ 


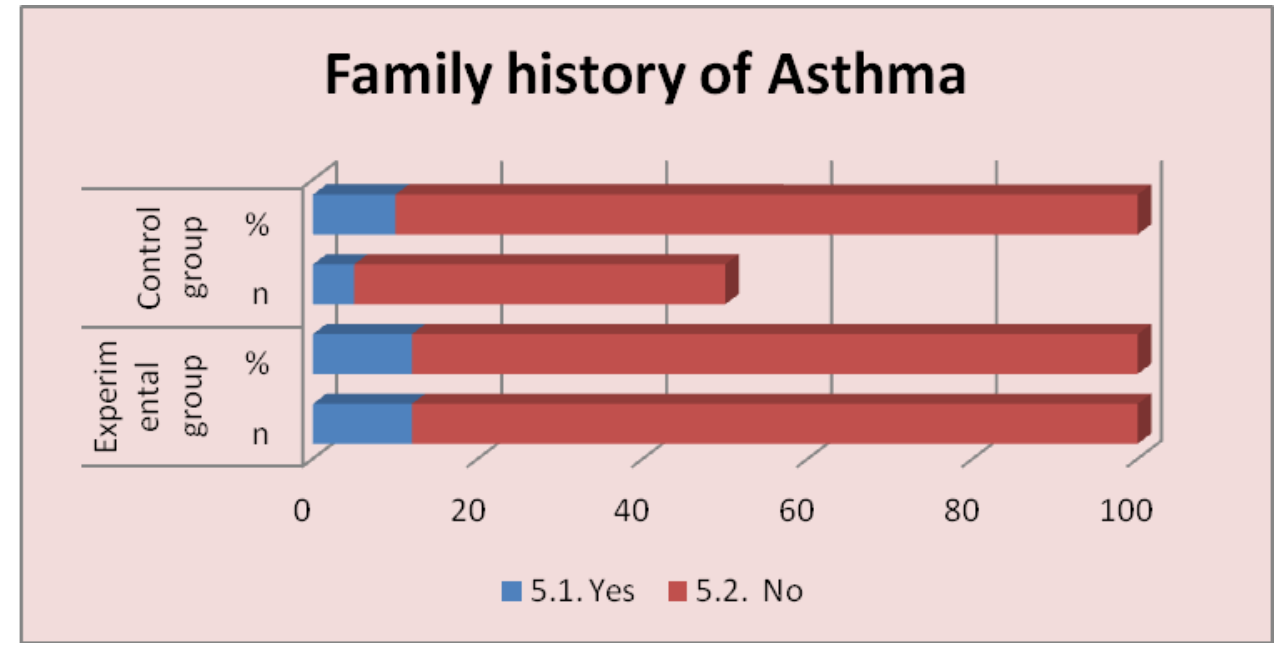

Fig 2: Distribution of Asthma Patients based on Family history

Fig (2) indicates $88 \%$ in the exp.gr and $90 \%$ in the Contr.gr not having any family history. Only $12-10 \%$ of them show positive history respectively.

$\mathrm{N}=150$

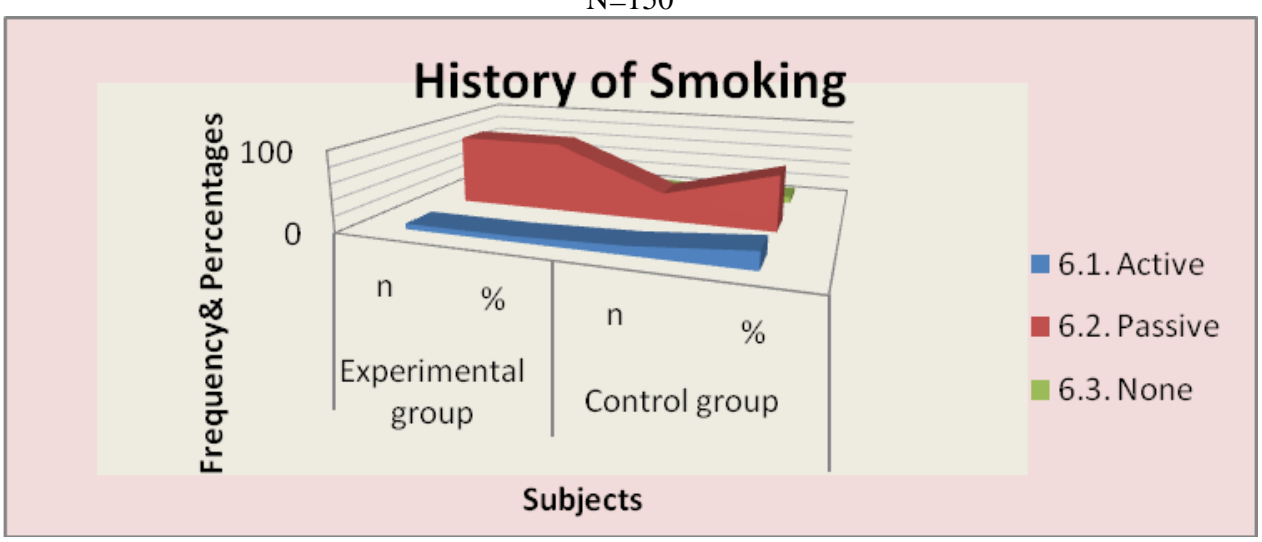

Fig 3. Distribution of bronchial asthma patients based on History of Smoking

Fig (3) Majority of the subjects' i.e. $88 \%$ in the experimental and $68 \%$ in the control groups were passive smokers and only 5 to $8 \%$ of them respectively reported of not exposed to smoking.

$$
\mathrm{N}=150
$$

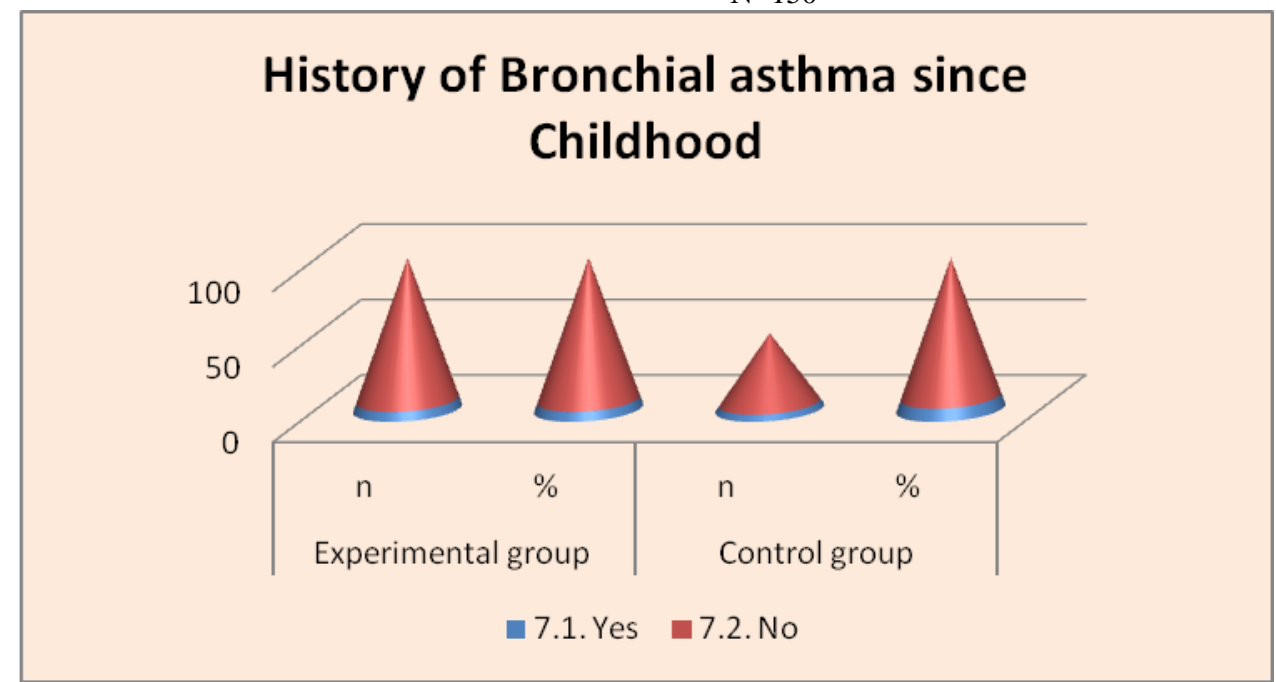

Fig 4.Distribution of asthma patients based on the history of asthma since Childhood

Only $6 \%$ and $8 \%$ of the asthma patients reported (Fig 4) positive history of childhood asthma in experimental and control groups respectively. 


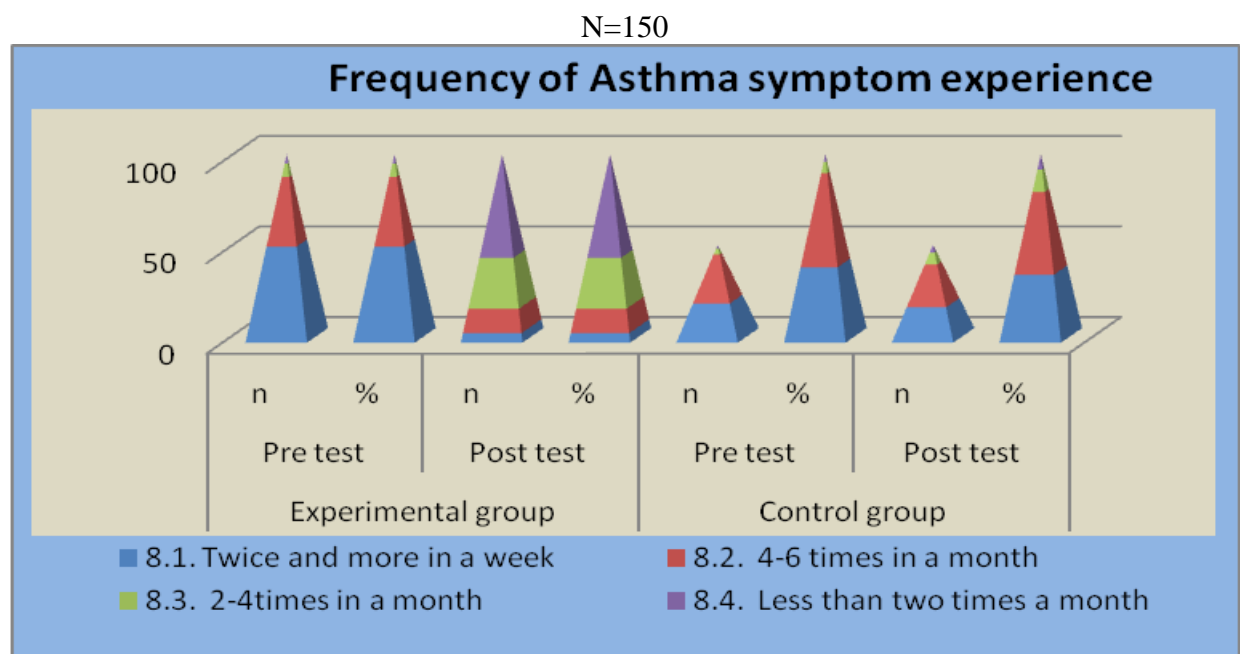

Fig 5. Distribution of asthma patients based on the frequency of symptom experience

Figure (5) shows a decline in number of patients experiencing symptoms more frequently after the nursing interventions in the experimental group, whereas the change in the control group post test was less remarkable.

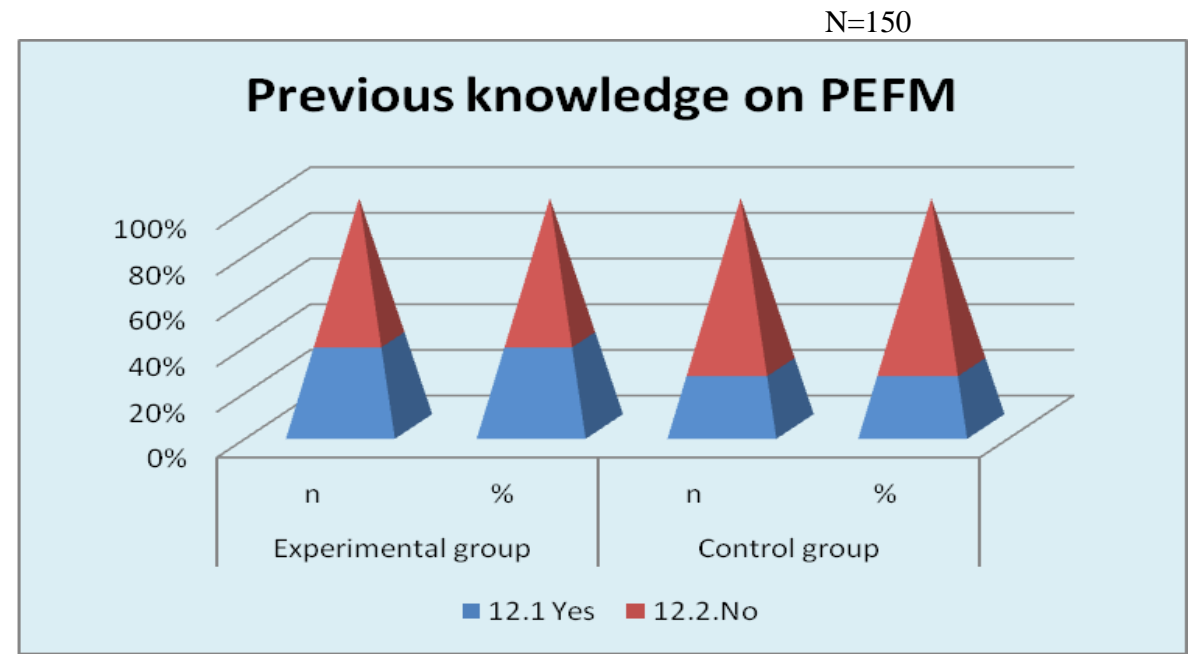

Fig 6. Distribution of asthma patients based on their previous knowledge on PEFM

The awareness on Peak flow monitoring was reported( Fig 6) positive about $7 \& 8 \%$ in the experimental and control groups respectively before participating in the study.

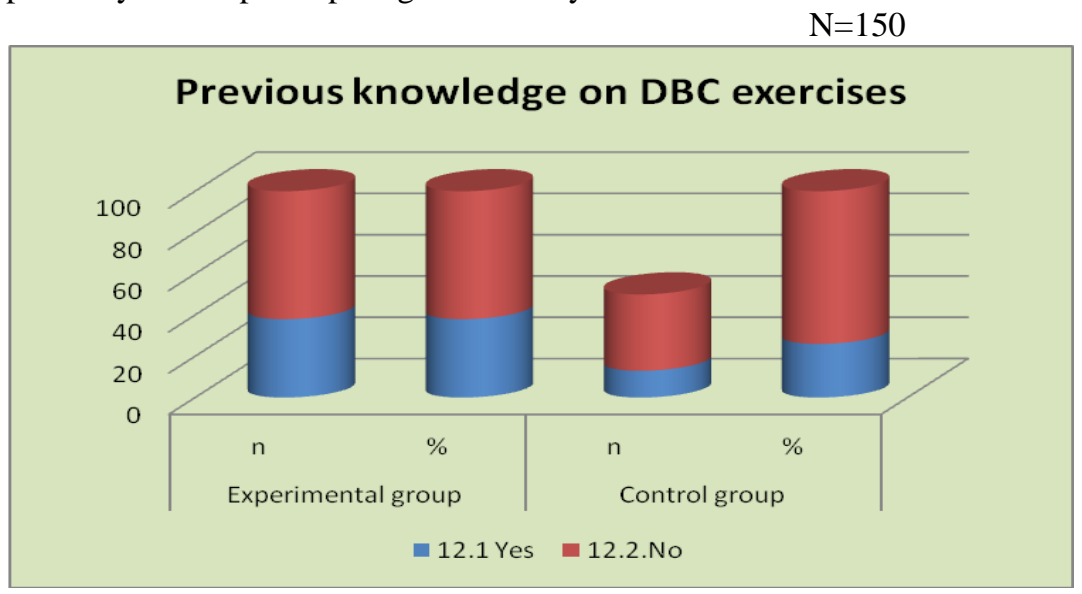

Fig 7: Distribution of asthma patients based on their previous knowledge on DBC exercises

About $38 \%$ in the experimental and $26 \%$ in the control group subjects have reported to know about Deep breathing and coughing exercises before the study (Fig7).

DOI: $10.9790 / 1959-0602070513 \quad$ www.iosrjournals.org $\quad 9 \mid$ Page


Table 1: Distribution of ' $\mathrm{t}$ ' values according to the areas of Practices in the Experimental Group subjects with Bronchial Asthma;

\begin{tabular}{|c|c|c|c|c|c|c|c|c|}
\hline \multirow{2}{*}{$\begin{array}{l}\mathrm{S} . \\
\mathrm{NS} \\
. \mathrm{N} \\
\mathrm{o}\end{array}$} & \multirow{2}{*}{$\begin{array}{l}\text { Components of } \\
\text { Practice }\end{array}$} & \multirow{2}{*}{$\begin{array}{l}\text { Pre-test } \\
\text { Mean } \pm \text { S.D }\end{array}$} & \multirow{2}{*}{$\begin{array}{l}\text { Post- test } \\
\text { Mean } \pm \text { S.D }\end{array}$} & \multicolumn{2}{|l|}{ SEM } & \multirow[t]{2}{*}{$\begin{array}{c}\text { Mean } \\
\text { difference }\end{array}$} & \multirow[t]{2}{*}{ ' $t$ ' value } & \multirow[t]{2}{*}{ "p" value } \\
\hline & & & & Pre test & Post test & & & \\
\hline 1 & Peak flow monitoring & $4.57 \pm 1.409$ & $8.79 \pm 1.604$ & 0.141 & 0.160 & 4.220 & 33.928 & $0.000 * *$ \\
\hline 2 & Inhalation technique & $3.26 \pm 1.300$ & $6.42 \pm 1.492$ & 0.130 & 0.149 & 3.160 & 24.594 & $0.000 * *$ \\
\hline 3 & $\begin{array}{l}\text { Deep breathing and } \\
\text { Coughing exercises }\end{array}$ & $3.05 \pm 1.009$ & $6.96 \pm 1.943$ & 0.101 & 0.194 & 3.910 & 25.208 & $0.000 * *$ \\
\hline 4 & Total Practices & $10.88 \pm 2.753$ & $22.17 \pm 3.872$ & 0.275 & 0.387 & 11.290 & 39.456 & $0.000 * *$ \\
\hline
\end{tabular}

** Significance at 'p' $<0.001$

The table (1) shows higher ' $t$ ' values in all the areas of Post test indicating the significant impact of the selected nursing interventions among experimental group of asthma patients in the specified areas at $\mathrm{p}<0.001$ level of significance. The total mean scores were higher in the post test scores (22.17) than the pre test practice mean scores (10.88), which signifies the effectiveness of selected nursing interventions on the practices of Bronchial asthma patients in the experimental group.

$\mathrm{N}=150$

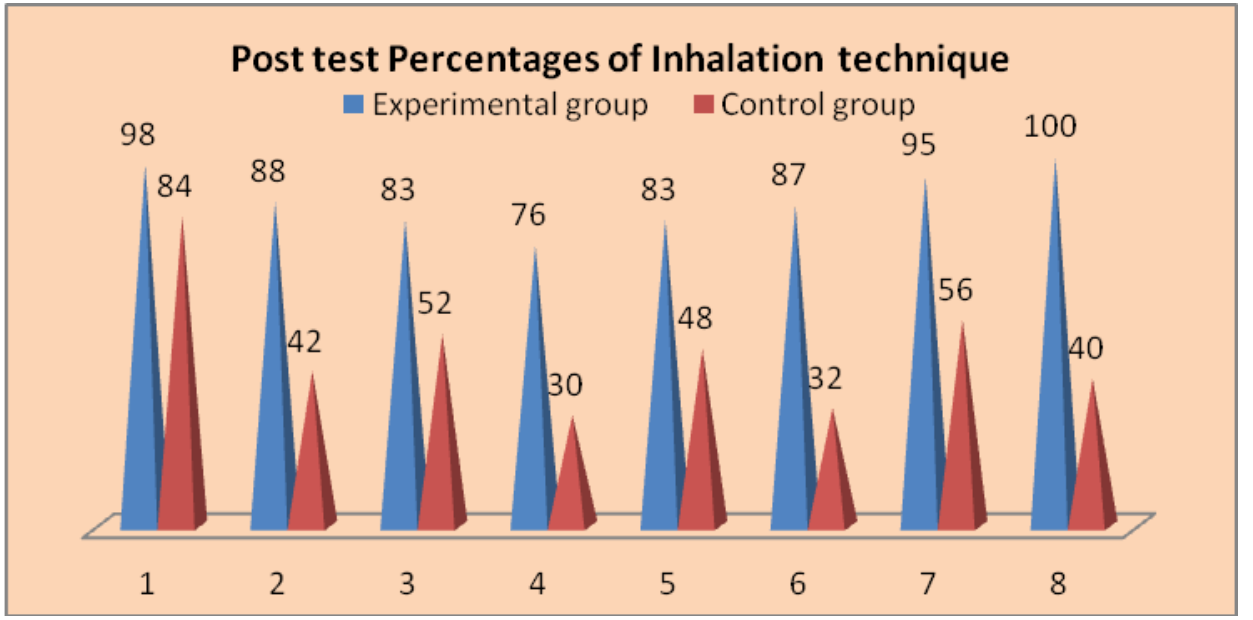

Fig 8: Distribution of stepwise Post test Percentages of Inhalation technique in experimental and control group of Asthma patients;

Stepwise performance scores of inhalation technique (Fig.8) in the post test show significant difference between experimental and control groups, with the experimental practice of the technique ranging between 76-100; the control group practices between $30-84$.

Table 2: Distribution of Step wise Performance of Peak flow monitoring in the Bronchial asthma patients:

\begin{tabular}{|c|c|c|c|c|c|c|c|c|}
\hline \multirow{2}{*}{ Step No } & \multicolumn{3}{|c|}{ Exp.Group } & \multicolumn{2}{c|}{ Contr.Group } \\
\cline { 2 - 9 } & Pre test & \multicolumn{2}{c|}{ Post test } & \multicolumn{2}{c|}{ Pre test } & \multicolumn{2}{c|}{ Post test } \\
\cline { 2 - 10 } & $\mathrm{n}$ & $\%$ & $\mathrm{n}$ & $\%$ & $\mathrm{n}$ & $\%$ & $\mathrm{n}$ & $\%$ \\
\hline 1 & 62 & 62 & 97 & 97 & 30 & 60 & 38 & 76 \\
\hline 2 & 65 & 65 & 99 & 99 & 32 & 64 & 38 & 76 \\
\hline 3 & 16 & 16 & 89 & 89 & 15 & 30 & 11 & 22 \\
\hline 4 & 20 & 20 & 85 & 85 & 09 & 18 & 09 & 18 \\
\hline 5 & 13 & 13 & 83 & 83 & 05 & 10 & 05 & 10 \\
\hline 6 & 19 & 19 & 92 & 92 & 05 & 10 & 14 & 28 \\
\hline 7 & 11 & 11 & 86 & 86 & 09 & 18 & 10 & 20 \\
\hline 8 & 20 & 20 & 86 & 86 & 08 & 16 & 11 & 22 \\
\hline 9 & 33 & 33 & 94 & 94 & 14 & 28 & 10 & 20 \\
\hline
\end{tabular}

Table (2) indicates stepwise performance of Peak flow monitoring in the intervention group. Though the awareness in the pre test was reported to be $6 \%$, the initial two steps of placing the indicator at the base of the numbered scale and standing upright was performed 62 to $65 \%$ in the pre test; other steps with least scores recorded of $11 \%$ raised to $88 \%$ with mean percentage of $90.1 \%$. 
Table 3: Step wise Performance of Deep breathing and coughing exercise in the experimental and control group of Bronchial asthma subjects; $\mathrm{N}=150$

\begin{tabular}{|c|c|c|c|c|c|c|c|c|}
\hline \multirow{2}{*}{ Step No } & \multicolumn{3}{|c|}{ Exp.Group } & \multicolumn{2}{c|}{ Contr.Group } & \multicolumn{2}{c|}{ Post test } \\
\cline { 2 - 9 } & \multicolumn{2}{|c|}{ Pre test } & \multicolumn{2}{|c|}{ Post test } & \multicolumn{2}{c|}{ Pre test } & \multicolumn{2}{c|}{ \% } \\
\cline { 2 - 9 } & $\mathrm{n}$ & $\%$ & $\mathrm{n}$ & $\%$ & $\mathrm{n}$ & $\%$ & $\mathrm{n}$ & $\%$ \\
\hline 1 & 90 & 90 & 99 & 99 & 43 & 86 & 47 & 92 \\
\hline 2 & 71 & 71 & 97 & 97 & 34 & 64 & 41 & 82 \\
\hline 3 & 36 & 36 & 87 & 87 & 21 & 42 & 22 & 44 \\
\hline 4 & 34 & 34 & 77 & 77 & 17 & 34 & 15 & 30 \\
\hline 5 & 52 & 52 & 82 & 82 & 27 & 54 & 27 & 54 \\
\hline 6 & 23 & 23 & 77 & 77 & 14 & 28 & 12 & 24 \\
\hline 7 & 39 & 39 & 84 & 84 & 15 & 30 & 21 & 42 \\
\hline 8 & 20 & 20 & 78 & 78 & 11 & 22 & 15 & 30 \\
\hline 9 & 48 & 48 & 96 & 96 & 20 & 40 & 27 & 54 \\
\hline 10 & 52 & 52 & 92 & 92 & 24 & 48 & 18 & 36 \\
\hline 11 & 50 & 50 & 99 & 99 & 15 & 30 & 21 & 42 \\
\hline
\end{tabular}

The above table (Table 3), depicts the step wise improvement in the deep breathing \& coughing exercise performances among the experimental subjects, where as only step $1 \& 2$ have been in the above average performance in the control group and with the lowest performance as 24 , the scores remain to be average in the control group of subjects.

$\mathrm{N}=150$

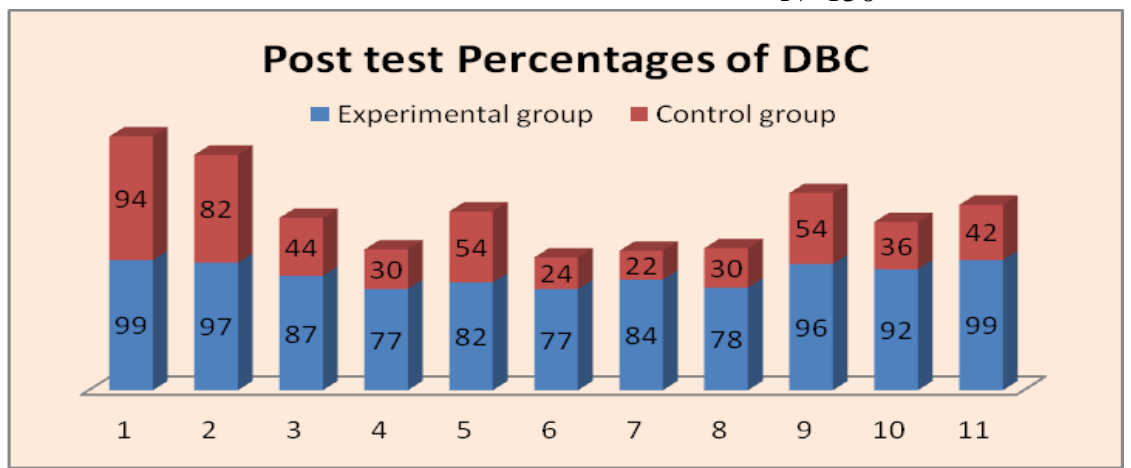

Fig 9: Distribution of Post test percentages of Deep breathing \& Coughing exercise performance in the experimental and control group of Bronchial asthma subjects;

Distribution of stepwise performance of Deep breathing and coughing exercise (Fig.9) and post test percentages (Fig 20), show the range of performing the right practice in the experimental group range between $20-90 \%$ in the pre test and it was enhanced to 77-99\% in the post test; Whereas in the control group the scores in the post test were ranging between 24-92.

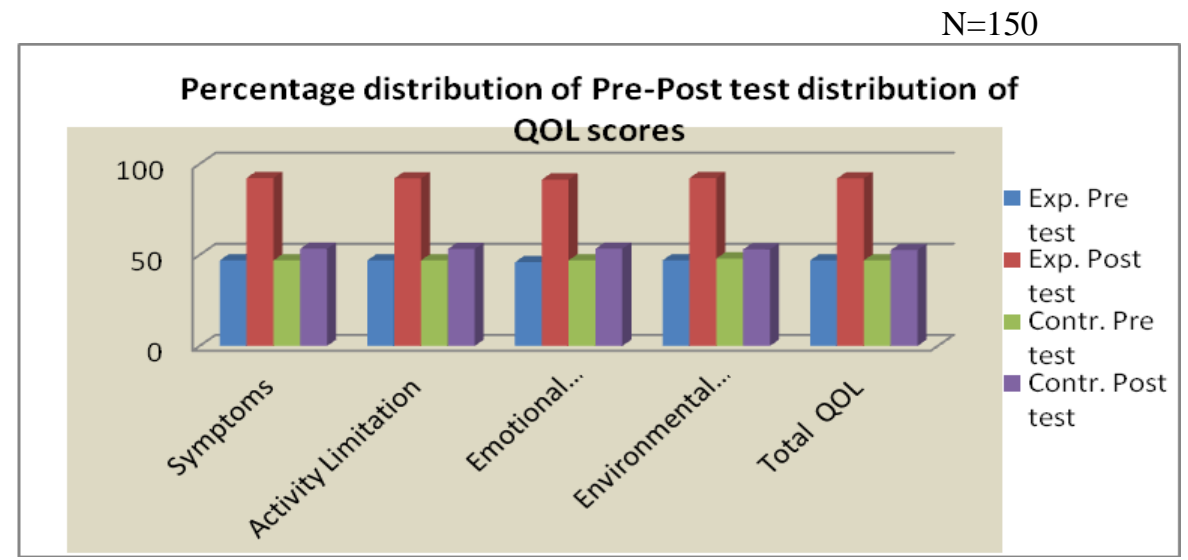

Fig 10: Domain wise distribution of QOL scores in the experimental and control group Of Bronchial asthma subjects;

Figure (10) shows $87 \%$ of the subjects in the adequate practices in the experimental group in the post test and Quality of life was maximum $96 \%$ in the average level in the control group, Table(18) indicate a vivid enhancement in the post test QOL distribution in the experimental group subjects. 
Table.4: Percentage distribution of QOL Pre- Post test scores in the Experimental group;

\begin{tabular}{|l|l|l|l|}
\hline \multicolumn{4}{|c|}{$\mathrm{n}=100$} \\
\hline Domain & Pre test \% & Post test 1\% & Post test 2\% \\
\hline 1. Symptoms & 47 & 74.86 & 92.28 \\
\hline 2. Activity Limitation & 46.9 & 73.67 & 88.96 \\
\hline 3. Emotional function & 45.57 & 74.14 & 91.57 \\
\hline 4. Environmental stimuli & 48.35 & 75 & 92.21 \\
\hline Total & 46.18 & 75.07 & 78.37 \\
\hline
\end{tabular}

$\mathrm{N}=150$

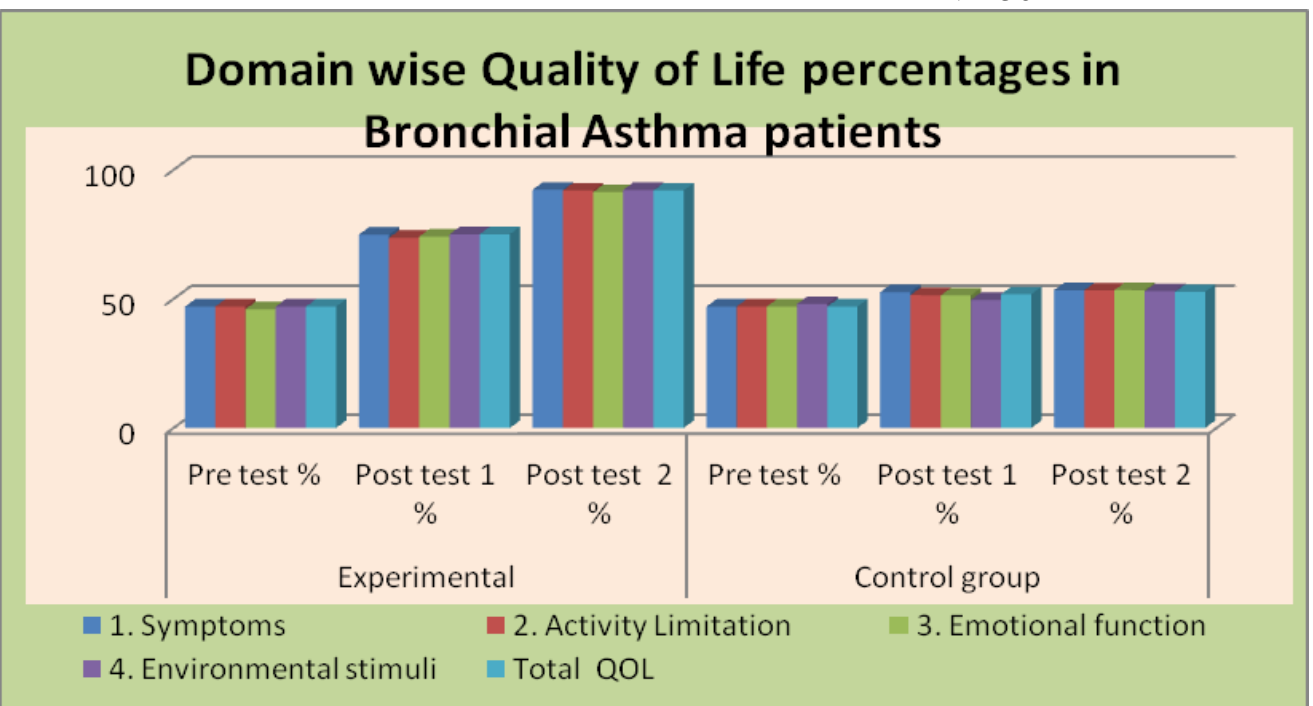

Fig 11: Percentage Distribution according to the QOL domains in the experimental and control group of Bronchial asthma patients;

Domain wise percentages of quality of life (Fig 11) in the experimental group show significant enhancement in all the individual domains and in total; the percentages (Table 24) in Symptoms the pre test percentage enhanced from 47 to 92 in the post test 2. The rise is from 47 to 89 in the domain of Activity limitation. The post test 2 was much higher (91.6) to pre test (45.6) in the Emotional function domain. In the Environmental domain the pre test percentages improved from 48 to 92.2. The QOL in overall improved from 46 to 78.37 in post test 2 , supporting the effectiveness of selected nursing interventions on QOL.

Table.5: Comparison of Mean \pm S.D and F values of QOL Pre test with Post test $1 \& 2$ between the experimental \& control group of subjects by ANOVA; $\mathrm{N}=150$

\begin{tabular}{|c|c|c|c|c|c|c|}
\hline QOL Domains & $\mathrm{p}^{\text {Grou }}$ & Pre test & Post test 1 & Post test 2 & $\begin{array}{c}\text { F } \\
\text { VALUE }\end{array}$ & $\begin{array}{l}\text { 'p' } \\
\text { value }\end{array}$ \\
\hline \multirow[t]{3}{*}{ 1.Symptoms } & & Mean \pm S.D & Mean \pm S.D & Mean \pm S.D & & \\
\hline & E.G & $39.530 \pm 3.644$ & $62.22 \pm 3.007$ & $75.410 \pm 7.569$ & 1241.030 & $0.000 * *$ \\
\hline & C.G & $39.660 \pm 3.217$ & $43.360 \pm 3.102$ & $44.240 \pm 2.387$ & 34.515 & \\
\hline \multirow{2}{*}{$\begin{array}{l}\text { 3.Activity } \\
\text { Limitation }\end{array}$} & E.G & $36.110 \pm 3.803$ & $56.130 \pm 3.152$ & $69.710 \pm 4.949$ & 1753.248 & $0.000 * *$ \\
\hline & C.G & $36.280 \pm 2.223$ & $40.000 \pm 2.424$ & $40.540 \pm 2.224$ & 51.185 & \\
\hline \multirow{2}{*}{$\begin{array}{l}\text { 3.Emotional } \\
\text { function }\end{array}$} & E.G & $15.950 \pm 2.240$ & $25.960 \pm 1.286$ & $31.880 \pm 1.976$ & 1838.902 & $0.000 * *$ \\
\hline & C.G & $16.280 \pm 2.214$ & $18.040 \pm 1.484$ & $18.460 \pm 1.388$ & 22.224 & \\
\hline \multirow{2}{*}{$\begin{array}{l}\text { 4.Environmental } \\
\text { stimulation }\end{array}$} & E.G & $13.270 \pm 1.705$ & $21.000 \pm 1.356$ & $25.680 \pm 1.740$ & 1516.022 & $0.000 * *$ \\
\hline & C.G & $13.340 \pm 1.319$ & $14.640 \pm 1.549$ & $14.840 \pm 1.149$ & 18.229 & \\
\hline \multirow[t]{2}{*}{ 5.Total QOL } & E.G & $104.860 \pm 9.393$ & $165.310 \pm 6.305$ & $202.680 \pm 14.027$ & 2251.095 & $0.000 * *$ \\
\hline & C.G & $105.560 \pm 7.456$ & $116.040 \pm 5.911$ & $118.080 \pm 4.370$ & 61.789 & \\
\hline
\end{tabular}

** Significant at $\mathrm{p}<0.001$

QOL Domain wise comparison of F value between E.G and C.G shows significant high values in the E.G; Table (5) shows domain wise F values by ANOVA; In the area of Symptoms the F value was higher (124.030 and 34.515) in E.G than C.G; The F value was significantly high in the E.G than C.G (1753.24 and $51.185)$ in the domain of Activity limitation. The F value in E.G was 1838.902 in E.G, which is higher to $F$ value of C.G (22.224). In the Emotional function domain. In the Environmental domain the F value of E.G (1516.022/ 18.229) was much higher than C.G. The QOL in over all show the F value significantly higher in E.G to C.G( 2251.095 and 61.789) supporting the effectiveness of selected nursing interventions on QOL in the experimental group compared to the Control group. 


\section{Discussion}

The mean practice scores for the experimental group (22.17), was much higher than the mean practice scores of Control group (9.64) with ' $t$ ' value 21.398 at $\mathrm{p}<0.001$ level of significance. The base line QOL scores in the experimental (104.8 \pm 9.393$)$ group with the control group QOL scores $(105.56 \pm 7.45)$ doesn't show much variation, but the post test QOL scores between experimental (202.28 \pm 14.027$)$ and control group (118.08 \pm 4037$)$ scores with 't' value 41.589 at $p<0.001$ level of significance, reveal significant improvement in the experimental group supporting a positive influence of the selected nursing interventions. There was a significant improvement within the pre test $(3.81 \pm 1.656))$ and Post test scores in the experimental group $(6.91 \pm 0.831)$ in use of inhalation technique. The post test means between experimental (6.94) and control groups (4.92) supports the significant enhancement in the performance of inhaler use in the experimental subjects. Knowledge of the experimental group after intervention was significantly raised in both Peak flow meter use (mean 3.5 and 7.71) and Deep breathing and coughing exercises (mean scores of 4.79 and 9.3). The study findings support the findings of Prabhakaran et al, $(2006)^{10}$, Mishra N (2005) ${ }^{11}$, Aggarwal A N.et al(2006) ${ }^{12}$,Kotwani S K et al,(2011) ,highlights the need for adequate patient education on disease process and management. A study by Hamdan AL-Jahdali et al $(2013)^{11}$ identifies improper use of asthma inhaler devices In $45 \%$ of the patients and was associated with irregular clinic follow-ups $(\mathrm{p}=0.0001)$, lack of asthma education $(\mathrm{p}=0.0009)$, uncontrolled asthma $(\mathrm{p}=0.001)$.

\section{Limitation And Recommendations}

The study has not included elderly patients above 60 years. Retention of information might be greater if follow up reinforcement would be enhanced for a period of 3 months and 6 months. Behavior modification may be assessed after on interval of 12 to 24 months and so on a long term basis. Outpatient and inpatient units for chronic conditions like asthma, being heavily crowded may not be feasible for educating patients. Doctors, Nurses and other health care team members may not be able to contribute in patient education while performing routine duties. Hence a patient education cell may be established in every level of health care setting on specific days in a week to equip patients and their families with adequate information on disease management.

\section{Acknowledgements}

The author is thankful to the authors institution for the encouragement to pursue research and thankful to the Medical Superintendent of the hospital in according permission to conduct the study and the academic activities coordinator and Nursing superintendent for their support. Author is thankful to the institutional heads permitting the pilot study and special thanks to all the participants of the study.

\section{Unding Statement:}

The Research received no specific grant from any funding agency in the public, private or non - profit sectors. Conflict of Interest:

No conflict of interest has been declared by the author.

\section{References}

[1]. Guidelines for management of asthma at primary and secondary levels of healthcare in India (2004-2005): WHO-GOI collaborative programme.

[2]. Global Strategy for Asthma Management and Prevention, Global Initiative for Asthma (GINA) 2009.

[3]. Juniper EF, Guyatt Gh, Ferrie PJ, Epstein RS. Evaluation of impairment of Health Related Quality of life in Asthma, development of a questionnaire for use in clinical trial. Thorax.1992; (47); 76- 83

[4]. Kotwani A, S.K.Chabra, Vandana Tayal, V.K.Vijayan,Quality of Asthma Management in an Urban Community in Delhi, India, Indian J Med Res,135(2);184-192.

[5]. Jindal SK Gupta D. Aggarwal AN. Aggarwal (World Health organization and government of India. Guidelines for management of asthma at primary and management of asthma at primary (2005) Indian Jchest Dis allied Sci 2005 47:309-43.

[6]. Gupta PP. Gupta KB. Awareness about the disease in asthamatic patients receiving treatment from physicians at different levels. Indian J Chest Dis Allied Sci 2001:43:91-5

[7]. Bedi Rs. Knowledge about asthma and its management in asthmatics of rural Punjab. Indan J Tub 1993:40:153-5

[8]. Haughney J, Price D, Barnes NC, Virchow JC, Roche N, Chrystyn H. Choosing inhaler devices for people with asthma: current knowledge and outstanding research needs. Respir Med 2010;104(9):1237-45.

[9]. Khassawneh BY, Al-Ali MK, Alzoubi KH, Batarseh MZ, Al-Safi SA, Sharara AM, et al. Handling of inhaler devices in actual pulmonary practice: Metered-dose inhaler versus dry powder inhalers. Respir Care 2008;53(3):324-8.

[10]. Prabhakaran L, Lim G, Abisheganaden J, Chee CBE, Choo YM, Impact of an Asthma education programme on patients' knowledge, Inhaler technique and compliance to treatment. Singapore Med J; 2006; 47(3):225-31.

[11]. Mishra N, Rao KVR, Padhi SK. Asthma education for better compliance in disease management. Indian J Allergy Asthma Immunol ; 2005; (19): 25-8.

[12]. Aggarwal AN, Chaudhry K, Chhabra SK, et al,2006, Prevalence and Risk factors for Bronchial Asthma in Indian adults: a multicenter study. Indian J Chest Dis Allied Sci; (48); 13-22.

[13]. Nadia M,Taha Zeinab H Ali, Effect of Therapeutic guidelines for Bronchial Asthma in adult patients' knowledge, practices, Compliance and disease severity; Life science journal; 2011; 8(3); 199-208

[14]. Barthwal MS, CDS Katoch, V Marwah, Impact of Optimal Asthma Education Programme on asthma Morbidity, Inhalation Technique and Asthma Knowledge JAPI • August 2009 (57): 574-579

[15]. Bousquet J, Philippe J,Bousquet, Philippe Goddard and Jean Pierre Doures, 2005, The Public HealthImplications of Asthma, WHO bulletin, 2005; 83(7); 548-54. 